\title{
Serebral palside spastisitenin medikal ve cerrahi tedavisi
}

\author{
Medical and surgical treatment of spasticity in cerebral palsy
}

\author{
Burcu Göker
}

İstinye Üniversitesi Tıp Fakültesi, Beyin ve Sinir Cerrahisi Anabilim Dalı, Liv Hospital Ulus, Beyin ve Sinir Cerrahisi Kliniği, İstanbul

\begin{abstract}
Serebral palsi, çocuklarda spastisite ve fiziksel engelliliğin en sık nedenidir. Etiyolojisi çok çeşitlilik gösterir. Tedavi stratejisini belirlemede mutlaka multidisipliner bir yaklaşım benimsenmelidir. Tedavi seçenekleri arasında medikal tedavi, fizik tedavi ve cerrahi tedaviler bulunmaktadır. Bu yazıda serebral palside spastisitenin yönetilmesinde kullanılan güncel tedavi seçenekleri özetlenmiştir.
\end{abstract}

Anahtar sözcükler: serebral palsi; spastisite; intratekal baklofen pompası; selektif dorsal rizotomi; selektif nörotomi; DREZ operasyonu; stereotaktik girişimler
Cerebral palsy is the most common cause of spasticity and physical disability in children. Its etiology has a great variety. A multidisciplinary approach is needed regarding the patient management, while planning the treatment strategy. The treatment options include medical treatment, physical therapy, and surgical interventions. Herein we summarized the current treatment options utilized for the management of spasticity in cerebral palsy.

Key words: cerebral palsy; spasticity; intratechal baclofen pump; selective dorsal rhizotomy; selective neurotomy; DREZ operation; stereotactic procedures pastisite; serebral korteks, beyin sapı ya da spinal kordun diffüz ya da lokalize patolojileri sonucunda ortaya çıkar. Spastik hastaların yaklaşık 2/3'ünün etiyolojisinde serebral palsi (SP) yer almaktadır. Spastisite ciddi kafa travmaları, serebrovasküler hastalıklar, hipoksi ve spinal kord yaralanmaları sonrasında da sık görülen bir tablodur.

Serebral ya da spinal kaynaklı tüm spastisitelerin fizyopatolojisinde ana etken, eksitatör ve inhibitör mekanizmalarda gelişen bir dengesizliktir. İnhibitör nörotransmitter olan gamma-aminobutirik asit (GABA)'in rölatif olarak eksilmesi, inhibitör uyarıların azalmasına neden olur. Tedavi de bu inhibisyon mekanizmasını tekrar devreye sokmak üzerine kurgulanır. Güncel cerrahi yaklaşımda en sık kullanılan baklofen pompası implantasyonunun mantığı, GABA agonistinin doğrudan intratekal alana verilmesi ile eksik olan inhibitör nörotransmitterin replase edilmesidir. Rizotomide ise inhibitör nörotransmitterin arttırılması değil, afferent eksitatör uyarıların azaltılması amaçlanır. ${ }^{[1,2]}$

SP, bebeklikte ya da çocukluk çağının başlarında ortaya çıkan, vücut hareketlerini ve kas koordinasyonunu kalıcı şekilde etkileyen nörolojik bir hastalıktır. Statik bir ensefalopati olarak da ifade edilebilir. Beynin erken dönemdeki gelişimi sırasında oluşan lezyon büyüme ve gelişmeye bağlı olarak klinik bulgu verebilir. SP'nin etiyolojisinde prenatal, perinatal ve postnatal risk faktörleri yer alır. Hastaların \%75-80'lik oranı prenatal dönemde etkilenir. Bunların ise \%10'dan daha az bir kısmı doğum travmaları ve asfiksi kaynaklıdır. En önemli risk faktörü prematürite ve buna bağlı düşük doğum ağırlığıdır. ${ }^{[3]}$

SP görülen çocukların çoğunluğu bu bozuklukla doğar, ancak bozukluk aylar ya da yıllarca tespit edilemeyebilir. Motor fonksiyonlarda bozukluğun yanında, duyu bozuklukları, zekâ geriliği, davranış bozuklukları, öğrenme güçlükleri, dil-konuşma bozuklukları ve ağız diş problemleri de görülebilir. Serebral palsi birlikteliğindeki spastisiteye bir yaş altında tanı konması oldukça güçtür. ${ }^{[1]}$

Spastisite; artmış tonus, hiperaktif refleksler, güçsüzlük ve zayıf koordinasyon gibi birden fazla bulgunun oluşturduğu bir klinik tablodur. Tedavisindeki amaçlar; tonusu azaltmak, ağıı ve spazmı azaltmak, eklem

- İletişim adresi: Yrd. Doç. Dr. Burcu Göker, Ahmet Adnan Saygun Cad. Canan Sok. No:5, Ulus-Beşiktaş, İstanbul Tel: 0212 - 9998099 e-posta: burcugoker79@yahoo.com

- Geliș tarihi: 1 Ekim $2018 \quad$ Kabul tarihi: 1 Ekim 2018 
hareket açıkığını arttırmak, kontraktür gelişimini engellemek, rehabilitatif yaklaşımın kolay uygulanmasını sağlamak, ortez kullanımı için uygunluğu arttırmak, ortopedik girişim ihtiyacını azaltmak ve kozmetik görünüşü iyileştirmektir.

Spastisite tedavisinde kullanılan yöntemler; medikal tedavi, intratekal baklofen uygulamaları, botilinum toksin enjeksiyonları, fizik tedavi, ortopedik düzeltme operasyonları ve nöroşirürjik girişimlerdir.

\section{MEDIKKAL TEDAVi}

Spastisitenin medikal tedavisinde kullanılabilecek çok sayıda ajan mevcuttur. Buradaki mantık, oral alınan ilaçların spinal korda geçişi ile eksitatör nörotransmitterlerin inhibisyonu ya da inhibitör transmitterlerin arttırılmasını sağlayarak vücut tonusunun azaltılmasıdır. ${ }^{[2]}$ Bu ilaçların biyo-yararlanımı da düşüktür. Örneğin oral baklofenin lipid çözünürlüğü düşük olduğundan, kan-beyin bariyerini zayıf şekilde geçer. Bunun sonucu, klinik etkiye ulaşabilmek için yüksek dozda oral ilaç kullanımının gerekmesidir ve bu noktada çeşitli sorunlar başlar. Ayrıca, bu ilaçlar merkezi sinir sisteminde sadece spinal kord düzeyinde etki göstermez. Oral alımı olan ilaçların bilinen en önemli yan etkileri, sedasyon ve bilişsel defisitlerdir. Bunun nedeni de etkilenen beyindeki nörotransmitter değişiklikleridir. Bu değişiklikler her zaman, spastisitenin azalmasından önce sedasyona yol açar. ${ }^{[2,4]}$ Oral yoldan alınan ilaçların SP tedavisinde kullanım sırasını belirleyen bir kılavuz yoktur, ancak klinik pratikte sedasyon etkisi en az olan oral baklofen, ilk basamak ilaç olarak tercih edilmektedir. ${ }^{[4]}$ ikinci basamakta ise benzodiazepinler tercih edilir. Diğer ilaçlar ise daha seyrek ve bahsedilen tedavilere yanıt olmadığı durumlarda tercih edilir.

\section{Medikal Tedavi Seçenekleri}

\section{Baklofen}

Presinaptik GABA-B agonistidir ve $P$ maddesi antagonistidir. Etki mekanizması spinal kord arka boynuzdaki motor nöronlarda ekstitatör nörotransmitter salınımını inhibe etmektir. Günde üç kez, 2,5-40 mg dozlarda kullanilır. Ataksi, konfüzyon, hipotansiyon, güçsüzlük, mide bulantısı, konstipasyon, paresteziler ve sedasyon gibi çok sayıda yan etkisi bulunur. Tedavi hiçbir zaman ani kesilmemelidir. Yoksunluk semptomları, kesildikten 1-3 gün sonra ortaya çıkabilir. Bunlar, artan spastisite, hipertermi, kan basıncında labilite, disfori, pruritus ve paresteziler, genel kas sertliği ve nöbetlerdir. Ağır olgularda ise deliryum, konfüzyon, rabdomiyoliz, organ yetersizlikleri, dissemine intervasküler koagülopati (DiK) ve hatta ölüm olabilir. Yoksunluk tedavisinde oral veya intravenöz benzodiazepinler, tizanidin (oral antispazmodik), kaşıntı için siproheptadin ve dantrolen kullanılabilir.

\section{Benzodiazepinler}

Nöral transmisyonda inhibitör rol oynayan GABA etkilerini arttırır. Pre- ve post-sinaptik GABA A reseptörlerine bağlanır. Sedatif, anksiyolitik, antikonvülzan, amnestik ve kas gevşetici özellikleri vardır. Günde 3-4 kez 1-12 mg dozlarda uygulanır. Sedasyon, salya artışı, hipotansiyon, ataksi, davranışsal ve kognitif bozukluklar sık görülen yan etkileridir.

\section{Tizanidin}

Santral etkili bir alfa-2 adrenerjik reseptör agonistidir. Reseptörlere presinaptik olarak bağlanır ve motor nöron inhibisyonunu arttırır. Çocuklarda kullanım dozu tanımlanmamıştır. Ancak, erişkinde günde 2-4 kez $6 \mathrm{mg}$ dozuyla başlanır ve sonrasında günlük doz her 3-7 günde bir 2-4 mg arttırılır. Ortalama günlük doz 12-24 mg'dır. Böbrek ve karaciğer fonksiyonlarına dikkat edilmeli, yetmezlik durumunda kullanmaktan kaçınılmalıdır. Hipotansiyon, sedasyon, ağız kuruluğu ve bradikardi sık bildirilen yan etkileridir.

\section{Dantrolen}

Ryanodin reseptörlerini antagonize ederek sarkoplazmik retikulumdan kalsiyum salınımını inhibe eden ve postsinaptik kas gevşetici işlevi gören bir ajandır. Günümüzde malign hiperterminin birinci basamak ilacı olarak kullanılmakla birlikte, daha önceleri spastisite tedavisinde yaygın olarak kullanılmıştır. ${ }^{[5]}$ Spastisite tedavisinde günde 2-4 kez, 1-3 mg/ kg'lık dozlar halinde kullanılır. Santral sinir sistemine ait yan etkileri oldukça sıktır. Bunlar konuşma ve görme bozuklukları, konfüzyon, halüsinasyonlar, başağrısı, uykusuzluk, depresyon, nöbet sıklığında artıştır. Ayrıca iştahsızlık, bulantı-kusma, abdominal kramplar, diyare, karaciğer enzimlerinde yükselme, hepatit, güçsüzlük ve paresteziler de görülebilir.

\section{INTRATEKAL BAKLOFEN POMPASI (ITB)}

Baklofen, bilinen en etkili antispazm ilaçlardan GABA-B agonistidir. Spinal kordun dorsal boynuzlarından salınan majör inhibitör transmitterdir. Yağdaki zayıf çözünürlüğünden dolayı kan beyin bariyerine geçişi oldukça zor olan baklofeni direkt olarak spinal subaraknoid aralığa ulaştırmak santral sinir sisteminde çok daha etkili sonuçlar verir. Böylece, GABA bağımlı inhibisyon ile spastisite azaltılırken beyinde yüksek doz baklofenin oluşması engellenerek yan etkilerden kaçınılmış olunur. 
Bu işlemin uygulanması için gerekli endikasyonları şu şekilde sıralayabiliriz:

- Şiddetli spastisite (Ashwort 4-5).

- Oral antispazmotiklere cevap vermeme ya da yetersiz cevap.

- Oral antispazmotikler ile ciddi yan etki oluşumu.

- Dört yaş üstünde yeterli vücut kitlesine ulaşmış hasta.

- Serebral kökenli spastisitede olayın üzerinden bir yıl geçmiş olması.

- Enfeksiyonu ya da baklofen alerjisi olmayan hasta.

\section{- Pozitif baklofen test cevabı.}

Cerrahi öncesi tüm olgularda baklofen testi yapılır. Hastaya lomber ponksiyon yapılarak subaraknoidal mesafeye $50 \mathrm{mcg}$ dozunda baklofen verilir. İşlem sonrası dört saat içinde hasta her saat başı değerlendirilir ve tonüste düzelme olup olmadığına bakılır. Ashworth Skalası'na göre bir ya da daha fazla puan azalma ve ciddi bir yan etki görülmez ise hastaya pompa implantasyonu endikasyonu konulur. Eğer Ashworth Skalası'na göre bir ya da daha fazla puan azalma olmazsa ilaç dozu arttırılarak (2. gün $75 \mathrm{mcg}$, 3. gün 100 $\mathrm{mcg}$ ) test tekrarlanır. Ashworth skalasında düzelmenin olduğu değer, hastanın pompa takıldıktan sonra ortalama hangi dozda ilaçtan yarar göreceğini de gösterir.

Kateter lomber bölgeden (L3-4, L4-5 seviyesi) subaraknoid boşluğa gönderilir. Hastanın klinik tablosuna göre kateterin ucu floroskopi kontrolünde uygun seviyeye kadar çıkartılır. Spastik dipleji olgularında T1012, spastik tetraplejide C5-T2, jeneralize distonilerde C1-4 seviyesine yerleşmesi tercih edilir. Karın bölgesinde cilt altı ya da fasya altına pompa yerleştirilir. Pompanın batında yerleştirileceği taraf, aile ve hastayı takip eden fizyoterapist ile görüşülerek kararlaştırılmaII, ventrikülo-peritoneal şant, gastrostomi tüpü gibi ek yabancı cisimlerin varlığı değerlendirilmelidir. Bu hastalarda fizyoterapi programı da pompa implante edildikten sonra başlanmalıdır.

íki tip pompa mevcuttur. En sık kullanılan ayarlanabilir pompalar $20-40 \mathrm{~mL}$ hacme sahip olup infüzyon hızı dışardan programlanabilir. Hasta ve cerraha daha çok kolaylık sağlayan cihazlardır. Bir diğer ürün ise infüzyon hızının sabit olduğu ilaç doz ayarlamasının pompa içindeki ilaç derişiminin değiştirilerek yapıldığı pompalardır. Bunların tek avantajı ucuz olmalarıdır.

Komplikasyonları arasında; cerrahiye bağlı sorunlar (enfeksiyon, beyin-omurilik sıvısı fistülü), cihaza bağlı sorunlar (kateterin bükülmesi, tıkanması, sızdırması veya kateter-pompa bağlantısının çıkması) ve ilaç dozuna bağlı sorunlar (yeterli doza ulaşılamadığında halüsinasyon, nöbet, psikotik atak ve rebound spastisite; doz aşımında ise sersemlik, baş dönmesi, nöbet, solunum depresyonu ve komaya kadar ilerleyebilen bilinç kaybı) bulunmaktadır. ${ }^{[6]}$ Hasnat ve Rice'in 2015 yılında yaptığı Cochrane Veritabanı Taraması'na göre uzun dönemde intratekal baklofen pompasının komplikasyon oranı \%10 ila \%30 arasında değişmektedir. ${ }^{[7]}$ Bunlar büyük oranda cihaza veya katetere bağlı sorunlardır ve uzun dönemde ortaya çıkar. Yine aynı taramada cihaza bağlı sorunlar \%8 ila \%11 arasında, BOS fistülü ise \%3 ila \%17 arasında bildirilmiştir. ${ }^{[7]}$ Eşleştirmeli kohort bir çalışmada, 359 hastada yaşam beklentisi ve sürvi bakımından baklofen pompası tedavisinin mortalite riskini arttırmadığı ortaya konmuştur. ${ }^{[8]}$

\section{SELEKTIF DORSAL RIZOTOMi}

Alt ekstremitelerdeki spastisitenin lumbosakral dorsal rizotomi ile cerrahi tedavisi ilk kez Förster tarafından yirminci yüzyılın başlarında uygulanmıştır. ${ }^{[9-11]}$ Bu girişim ile olguların çoğunda spastisitenin azaldığı görülmüştür. Förster'in rizotomi tekniği son 40 yıl içinde, intraoperatif elektrofizyolojinin de kullanılmasıyla, Fasano ve daha sonra Peacock tarafindan selektif dorsal rizotomi (SDR) seklinde değiştirilmiştir. ${ }^{[9-12]}$ Peacock yöntemi, lumbosakral köklerin çıkış forameninde uygulanır.

SDR genellikle L1-S1, L2-S2 seviyelerinde yapılır ve posterior kökün \%20 ila \%70'i kesilebilir. L4 seviyesinde kuadriseps kasının tonüsünü korumak için göreceli olarak daha az kesilir. ${ }^{[13,14]}$ Eğer ayak bileğinde plantar fleksiyon spastisitesi varsa S2'nin parsiyel rizotomisi yapılır. Mesane ve perianal bölgenin fonksiyonların korumak için S2 posterior köklerinin \%35'inden fazlası kesilmez. ${ }^{[15]}$

Az cerrah tarafindan uygulanan L1 laminotomi tekniği ise daha zordur ve konusun zarar görme ihtimali daha yüksektir. Buna karşılık avantajları ise; daha kısa bir cilt insizyonu, daha az kas disseksiyonu, daha az laminanın kesilmesi ve konus düzeyinde dorsal ve ventral köklerin daha kolay ayırt edilebilmesidir. ${ }^{[16]}$

SDR, özellikle alt ekstremite spastisitesinin engelleyici rol oynadığı ve az miktarda üst ekstremite tutulumu olan çocuklarda tercih edilmelidir. SDR spastisite üzerine etkilidir, ancak distoni için bir yararı yoktur. Bu nedenle, progresif distoni gelişimi ihtimali yüksek olan beş yaş altı, spastik kuadriplejik birçok çocukta SDR önerilmemektedir.

SDR'nin sonuçlarının ayrıntılı olarak yayımlandığı çalışmalarda, alt ekstremite eklemlerinde hareket açıklığında çok belirgin düzelme olduğu, hareket edebilen hastaların hareket mesafesinin arttığı, adım 
mesafesinin uzadığına dair kanıtlar gösterilmiştir. ${ }^{[12,13]}$ Literatürde mevcut üç randomize çalışmayı kapsayan meta-analizde spastisite derecesi Ashworth skalası ile, motor fonksiyonlar ise Gross Motor Function Measure (GMFM) skalası ile değerlendirilmiştir. GMFM'de SDR sonrası belirgin iyileşme görülmüştür. SDR ve fizyoterapi birlikteliği olan grubun sadece fizyoterapi alan gruba göre istatiksel olarak belirgin biçimde iyileştiği ortaya konmuştur. ${ }^{[17]}$

SDR'nin cerrahi komplikasyon oranı oldukça düşüktür. Ameliyat sırasında en sık karşılaşılan problem bronkospazmdır. ${ }^{[18]}$ Ameliyat sonrası gelişebilecek komplikasyonlar arasında en önemlileri sıklıkla geçici olan üriner inkontinans ve uzun segment laminektomiye bağlı spinal deformite gelişimidir. ${ }^{[10,19]}$

\section{SELEKTIF NÖROTOMi}

Selektif nörotomi ya da başka deyişle selektif fasikülotomi, fokal spastisite varlığında kontraktürü olmayan olgularda uygulanabilen cerrahi bir yöntemdir. ilk kez Alfred Lorenz tarafindan, ileri kalça adduktor spastisitesi olan olgularda obturator sinir nörotomisi yapılmıştır. ${ }^{[2]}$ Yöntem, yıllar içinde intraoperatif stimülasyon uygulaması eklenerek güncelleştirilmiştir.

Fokal spastisitenin lokalizasyonuna göre hedef periferik sinir belirlenir. Burada amaç, spastik kası innerve eden sinirdeki fasiküllerin bir kısmının kesilmesidir. Ameliyat sırasında en çok dikkat edilmesi gereken husus, hedef periferik sinirde kısmi lezyonun motor dallara yapılması ve sensoriyal dalların korunmasıdır. Yanlışııkla sensöriyel dalların hasar görmesi sonucu de-afferentasyon ağrıları ortaya çıkar ki, bu ağrılar tedavisi en güç ağrı tipi olup hastanın yaşam kalitesinin düşmesine neden olur. ${ }^{[20]}$

Ameliyat öncesi lokal anestezi ile ultrasonografi eşliğinde hedef sinire test yapılması cerrahi başarı oranını arttırmaktadır. Böylelikle, hedef sinir devre dışı kaldığında ne olacağı ve hastanın bundan ne ölçüde yararlanacağı gözlenmiş olur.

Operasyon sırasında hedef sinir eksplore edilir ve vaskülarizasyonu bozulmadan fasiküller disseke edilir. Tüm lifler mutlaka ortaya çıkarılmalı ve stimülatör ile motor yanıtlara bakılmalıdır. Motor yanıtı en güçlü veren fasikül kesilerek yaklaşık $1 \mathrm{~cm}$ 'lik segment çıkarılır. Daha sonra ekstremite kontrol edilir. Gevşeme yetersiz ise, en güçlü motor yanıtı veren diğer fasikül de kesilir. Re-innerve olmaması için her iki uç bipolar yardımıyla yakılır.

Selektif nörotomi operasyonlarında en çok dikkat edilmesi gereken, hastanın mevcut duyu kapasitesini ve kas tonusunu koruyabilmektir. Tonus ortadan kaldırılırsa spontan dislokasyon riski ortaya çıkar. ${ }^{[21]}$ Intraoperatif monitorizasyon sırasında sinirin duyu dallarının ayrımı iyi yapılmalı ve korunmalıdır. Ayrıca, lezyon yeterli miktarda yapılmalı ve motor kuvetin istenmeyen oranda kaybolması engellenmelidir.

Spastisite fokal ise omuz spastisitesinde brakiyal pleksus selektif nörotomi; kolda belirgin spastisite için muskülokutanöz selektif nörotomi; önkol, bilek ve parmak spastisitesinde ulnar+median selektif nörotomi; kalça spastisitesi için, obturator nörotomi; diz spastisitesi için hamstring nörotomi; ayak spastisitesi için tibial nörotomi operasyonları önerilmektedir. ${ }^{[22]}$ Ayak bileğinin ekinus deformitesinde, soleus nörotomisi oldukça etkili bir role sahiptir. Decq ve ark., cerrahi sonrası uzun dönem takiplerinde tüm hastaların deformitelerinin düzeldiğini saptamışlardır. ${ }^{[23]}$

\section{DREZ OPERASYONU}

DREZ operasyonu; Dorsal Root Entry Zone'nun substantia gelatinoza ve arka kök giriş yerinde harap edilmesi esasına dayanır. De-afferentasyon ağrıları için ortaya atılmış etkili bir ameliyattır. Post-herpetik nevraljiler, post-paraplejik ağrılar, travmatik pleksus avulsiyonları sonrasında oluşan ağrılar ve fantom ağrıları bu tip ağrıya örnektir. 1972 yılında Sindou, tanımladığı yöntemde, posterior köklerin DREZ bölgesine giriş yerindeki lateral segmenti hedef olarak seçmiştir.[24] 1976 yılında Nashold tarafından DREZ'in mediyal bölgesi tanımlanmış ve farklı yöntemler gelişmiştir. ${ }^{[24]}$ Nashold modelinde bu bölgeye lezyon; $1 \mathrm{~mm}$ aralıklı ve $2 \mathrm{~mm}$ derinlikte, $75-80^{\circ} \mathrm{C}$ isıda, elektrod sistemleri ve radyofrekans enerjisinde yapılmaktadır. ${ }^{[25]}$ Her iki yöntem karşılaştırıldığında Nashold'un tekniğinde posterior köklere herhangi bir disseksiyon yapılmaksızın doğrudan DREZ lezyonu yapabilme üstünlüğü bulunmuştur.

De-afferentasyon ağrıları içinde önemli bir grubu post-paraplejik ağrılar oluşturmaktadır. Paraplejik ve yatalak erişkin hastalarda dorsal rizotomi veya DREZ tercih edilen ameliyat yöntemlerindendir. Üst ekstremite ve proksimalde belirgin hemispastik hastalarda DREZ + ulnar ve median nörotomi operasyonu yapılabilir. Çocuklarda belirli aralıklarla uygulanan botulinum toksin enjeksiyonları, üst ekstremite spastisitesinin tedavisinde oldukça tercih edilen bir yöntemdir. En büyük dezavantajı ise, bir süre sonra gelişen toksin direncidir. Bu metodun etkili olmadığı veya uygulanamadığı durumlarda, eğer spastisite omuz, kol, bilek ve parmakları tutuyor ise, nörotomi + DREZ operasyonu tercih edilebilir. Literatüre göre, DREZ operasyonlarında spastisite ve ağrılı spazmların ortadan kaldırılmasında başarı oranı \%60-80 oranında değişmektedir. ${ }^{[24,26]}$ 


\section{STEREOTAKTIK GIRIŞiMLER}

$\mathrm{SP}$, son derece çeşitli ve heterojen hasta gruplarını içeren geniş bir tanıdır. Hastalarda doğum sırasında yaşanan asfiksinin veya yenidoğan döneminde majör arteriyel yaralanmaların, bazı olgularda SP'nin nedeni olduğu gösterilse de, hastaların genel çoğunluğunda etiyoloji belirsiz kalmaktadır. ${ }^{[27]}$ Gelecekte, özellikle genetik alanındaki gelişmeler ile bu geniş "şemsiye-çatı" tanı adı kullanılmayacak, yerine her hastanın kendine özgü etiyolojik tanısı konacaktır. Ancak, bugün için SP'li hastaları, ön planda olan motor bozukluklarına göre dört ayrı alt gruba ayırmak mümkündür:

1) Spastik tip,

2) Ataksik tip,

3) Diskinetik tip ve

4) Mikst tip. ${ }^{[28]}$

Diskinetik tip hastalarda çeşitli derecelerde kore, atetoz veya distoni görülebilir. Sekonder distoninin çocukluk çağında en sık nedeni SP'dir. ${ }^{[29]}$ Burada asıl zorluk, erişkin hareket bozukluklarında olduğu gibi belirli bir istemsiz hareket paterni (örn; distoni, tremor vb.) olmaması, bunun yerine tüm hareket bozukluklarının hastaların çoğunda bir arada bulunmasıdır. Bu hastalar çoğunlukla medikal tedaviye de yanıtsızdır. O nedenle; her ne kadar tedavi için hedef belirlemede güçlüklere yol açsa da, diskinetik SP'li hastalar için stereotaktik girişimler etkin bir seçenek olabilir. Geçmişte bu amaçla sıklıkla, başta pallidotomi olmak üzere lezyon cerrahisi kullanılmaktayken, günümüzde derin beyin stimülasyonu (DBS) bu yöntemlerin yerini hemen tamamen almıştır. Yine de, hemidistonisi olan veya servikal distonisi olan seçilmiş olgularda pallidotomi tercih edilebilir. Distonisi ön planda olan SP'li olgular ile ilgili yapılan güncel bir literatür taramasında Elia ve ark., 1966-2017 yıllarını içeren MEDLINE taraması sonucu bu konuyla ilgili toplam 72 çalışma bulabilmişlerdir. Bunlar arasında ancak 12 çalışmanın taramaya dahil edilebilecek düzeyde veri içerdiğine karar vermişler ve toplam 124 hasta içeren bu çalışmaları taramalarına dahil etmişlerdir. ${ }^{[29]} \mathrm{Bu}$ çalışmalardaki hastaların ezici çoğunluğunda DBS için hedef yapı, diğer distonilerinde olduğu gibi globus pallidus internus (GPi) olarak bulunmuştur. Altı hastada iki yanlı GPi DBS'ye ek olarak tek taraflı talamotomi yapılmış, bir hastada iki yanlı GPi DBS'ye ek iki yanlı subtalamik nükleus (STN) DBS ve bir hastada ise talamusun ventral intermediate çekirdeği (Vim) hedeflenmiştir. Sonuçta iki ay ile $11 \mathrm{yıl}$ arasında değişen takip sürelerinde ve oldukça geniş varyasyon gösteren DBS pil ayarları ile (amplitüd 1-6,5 V, darbe genişliği $60-240 \mu \mathrm{s}$, frekans $30-185 \mathrm{~Hz}$ ) takip edilen bu hastalarda, sonuç üzerine etki eden tek parametre başlangıç aşamasındaki Burke-Fahn-Marsden distoni değerlendirme skalasındaki yüksek skorlar ile belirlenen distoninin ilerlemiş derecesidir. Yani ameliyat öncesi distoni düzeyi ne kadar ağır ise, bu hastalarda yanıt o kadar iyi bulunmuştur. [29] Ancak, başlangıç yaşı, semptomların süresi veya cerrahi sırasındaki yaşın önemi açıklanamamıştır. Bu nedenle, daha planlı, uzun süreli takip içeren çalışmalar yapılmadan, diğer distonilerde olduğu gibi daha net sonuçlar söylemek mümkün görünmemektedir. Ancak yine de, DBS SP'li hastaların cerrahi tedavisinde önemli bir seçenektir.

\section{SONUÇ}

Spastisite tedavisini belirlemede mutlaka multidisipliner bir yaklaşım gerekir. Hastanın hareket yeteneği, klinik ve radyolojik bulguları ile birlikte değerlendirilmelidir. Özellikle çocuklarda spastisite tedavisinde bir standart oluşturmak, yetişkin hastalara göre çok daha zordur. Çünkü çocuklarda büyüme devam etmekte ve ihtiyaçlar zamanla değişmektedir. Medikal ve cerrahi tedavi seçenekleri uygun şekilde planlandığında hasta ve aile için yüz güldürücü sonuçlar elde edilebilmektedir.

\section{KAYNAKLAR}

1. Albright AL, Pollack IF, Adelson PD, editors. Principles and Practice of Pediatric Neurosurgery, 2nd ed. New York: Thieme, 2008:1121-4.

2. Başarır $M$, Özek MM. Spastisite ve tedavisi. Türk Nöroşirürji Dergisi 2013;23(9):158-73.

3. Sankar C, Mundkur N. Cerebral Palsy -definition, classification, etiology and early diagnosis. Indian J Pediatr 2005;72(10):865-8. Crossref

4. Mete Civelek G, Atalay A. Serebral Palside Spastisite Tedavisi. J Curr Pediatr 2016;14(3):136-41. Crossref

5. Pinder RM, Brogden RN, Speight TM, Avery GS. Dantrolene sodium: a review of its pharmacological properties and therapeutic efficacy in spasticity. Drugs 1997;13(1):3-23. Crossref

6. Goldstein EM. Spasticity Management. An overview. J Child Neurol 2001;16(1):16-23. Crossref

7. Hasnat MJ, Rice JE. Intrathecal baclofen for treating spasticity in children with cerebral palsy. Cochrane Database of Syst Rev 2015;CD004552. Crossref

8. Krach LE. Complications associated with continuous infusion of intrathecal baclofen. Dev Med Child Neurol 1999;(suppl $80): 12$

9. Abbott R, Forem SL, Johann M. Selective posterior rhizotomy for the treatment of spasticity: A review. Child's Nerv Syst 1989;5(6):337-46. Crossref

10. Johnson MB, Goldstein L, Thomas SS, Piatt J, Aiona M, Sussman M. Spinal deformity after selective dorsal rhizotomy in ambulatory patients with cerebral palsy. J Pediatr Orthop 2004;24(5):529-36. Crossref

11. Steinbok P. Neurosurgical management of hypertonia in children. Neurosurgery Q 2002;12(1):63-78. Crossref 
12. Steinbok P. Outcomes after selective dorsal rhizotomy for spastic cerebral palsy. Child's Nerv Syst 2001;17(1-2):1-18. Crossref

13. Engsberg JR, Olree KS, Ross SA, Park TS. Spasticity and strength changes as a function of selective dorsal rhizotomy. J Neurosurg 1998;88(6):1020-6. Crossref

14. Engsberg JR, Ross SA, Collins DR, Park TS. Effect of selective dorsal rhizotomy in the treatment of children with cerebral palsy. J Neurosurg 2006;105(1):8-15. Crossref

15. Deletis V, Vodusek DB, Abbott R, Epstein FJ, Turndorf $\mathrm{H}$. Intraoperative monitoring of the dorsal sacral roots: minimizing the risk of iatrogenic micturition disorders. Neurosurgery 1992;30(1):72-5. Crossref

16. Park TS, Vogler GP, Phillips LH 2nd, Kaufman BA, Ortman MR, McClure SM, Gaffney PE. Effects of selective dorsal rhizotomy for spastic diplegia on hip migration in cerebral palsy. Pediatr Neurosurg 1994;20(1):43-9. Crossref

17. McLaughlin J, Bjornson K, Temkin N, Steinbok P, Wright $V$, Reiner A, Roberts T, Drake J, O'Donnell M, Rosenbaum P, Barber J, Ferrel A. Selective dorsal rhizotomy: meta-analysis of three randomized controlled trials. Dev Med Child Neurol 2002;44(1):17-25. Crossref

18. Farmer JP, Sabbagh AJ. Selective dorsal rhizotomies in the treatment of spasticity related to cerebral palsy. Childs Nerv Syst 2007;23(9):991-1002. Crossref

19. Hodgkinson I, Bérard C, Jindrich ML, Sindou M, Mertens $P$, Bérard J. Selective dorsal rhizotomy in children with cerebral palsy. Results in 18 cases at one year postoperatively. Stereotact Funct Neurosurg 1997;69(1-4):259-67. Crossref

20. Maarawi J, Mertens P, Luaute J, Vial C, Chardonnet N, Cosson M, Sindou M. Long term functional results of selective peripheral neurotomy for the treatment of spastic upper limb; Prospective study in 31 patients. J Neuorosurg 2006;104(2):215-25. Crossref
21. Steinbok $P$, Schrag $C$. Complications after selective posterior rhizotomy for spasticity in children. Pediat Neurosurg 1998;28(6):300-13. Crossref

22. Boyar B. Spastisitenin Cerrahi Tedavisi. Türk Nöroşirürji Dergisi 2014;24(2):209-12.

23. Decq $P$, Filipetti $P$, Cubillos $A$, Slavov V, Lefaucheur J-P, Nguyen J-P; Groupe d'Evaluation et de Traitement de la Spasticité et de la Dystonie. Soleus neurotomy for treatment of the spastic equinus foot. Neurosurgery 2000;47(5):115461. Crossref

24. Sindou M, Goutelle A. Surgical Posterior Rhizotomies for the Treatment of Pain. In: Advance and Technical Standards in Neurosurgery, Book Series Published by the European Association of Neurosurgical Societies, 1974-2016. 1983;10:147-85. Crossref

25. Kanpolat $Y$, Deda $H$, Başkaya $M$. Drez operasyonu. Türk Nöroşirürji Dergisi 1990;1:102-6.

26. Nashold BS, Ostdahl RH. Dorsal Root Entry Zone lesions for pain relief. J Neurosurg 1979;51(1):59-69. Crossref

27. Herskind A, Greisen G, Nielsen JB. Early identification and intervention in cerebral palsy. Dev Med Child Neurol 2015;57(1):29-36. Crossref

28. Tochen L, Singer HS. Movement disorders in children. In: Jankovic J, Tolosa E, editors. Parkinson's disease \& movement disorders 6th ed. Philadelphia, United States: Wolter Kluwer; 2015. pp.408-e19.

29. Elia AE, Bagella CF, Ferré F, Zorzi G, Calandrella D, Romito LM. Deep brain stimulation for dystonia due to cerebral palsy: A review. Eur J Paediatr Neurol 2018;22(2):308-15. Crossref 